Article

\title{
Sewer Mining as a Distributed Intervention for Water-Energy-Materials in the Circular Economy Suitable for Dense Urban Environments: A Real World Demonstration in the City of Athens
}

\author{
Argyro Plevri ${ }^{1, *}$, Klio Monokrousou ${ }^{1}$ (D), Christos Makropoulos ${ }^{1}$, Christos Lioumis ${ }^{2}$, Nikolaos Tazes ${ }^{2}$, \\ Efthymios Lytras ${ }^{3}$, Stylianos Samios ${ }^{3}$, Georgios Katsouras ${ }^{3}$ and Nikolaos Tsalas ${ }^{3}$ \\ 1 Department of Water Resources and Environmental Engineering, School of Civil Engineering, National \\ Technical University of Athens, Heroon Polytechneiou 5, 15780 Zografou, Athens, Greece; \\ kmonokrousou@gmail.com (K.M.); cmakro@mail.ntua.gr (C.M.) \\ 2 Chemitec, Water and Environmental Technologies, 23 Spirou Vrettou Str., 13671 Acharnes, Athens, Greece; \\ clioumis@chemitec.gr (C.L.); ntazes@chemitec.gr (N.T.) \\ 3 Athens Water Supply and Sewerage Company S. A (E.Y.D.A.P.)—Research and Development, 156 Oropou \\ Str., 11146 Galatsi, Athens, Greece; lytras@eydap.gr (E.L.); samios@eydap.gr (S.S.); gekats@eydap.gr (G.K.); \\ ntsal@eydap.gr (N.T.) \\ check for \\ * Correspondence: aplevri@central.ntua.gr; Tel.: +30-6947-546-646
}

updates

Citation: Plevri, A.; Monokrousou,

K.; Makropoulos, C.; Lioumis, C.;

Tazes, N.; Lytras, E.; Samios, S.; Katsouras, G.; Tsalas, N. Sewer Mining as a Distributed Intervention for Water-Energy-Materials in the Circular Economy Suitable for Dense Urban Environments: A Real World Demonstration in the City of Athens. Water 2021, 13, 2764. https:// doi.org/10.3390/w13192764

Academic Editors: Vasilis Kanakoudis and Stavroula Tsitsifli

Received: 3 September 2021

Accepted: 1 October 2021

Published: 6 October 2021

Publisher's Note: MDPI stays neutral with regard to jurisdictional claims in published maps and institutional affiliations.

Copyright: () 2021 by the authors Licensee MDPI, Basel, Switzerland. This article is an open access article distributed under the terms and conditions of the Creative Commons Attribution (CC BY) license (https:// creativecommons.org/licenses/by/ $4.0 /)$.

\begin{abstract}
Water reuse and recycling is gaining momentum as a way to improve the circularity of cities, while recognizing the central role of water within a circular economy (CE) context. However such interventions often depend on the location of wastewater treatment plants and the treatment technologies installed in their premises, while relying on an expensive piped network to ensure that treated wastewater gets transported from the treatment plant to the point of demand. Thus, the penetration level of treated wastewater as a source of non-potable supply in dense urban environments is limited. This paper focuses on the demonstration of a sewer mining (SM) unit as a source of treated wastewater, as part of a larger and more holistic configuration that examines all three 'streams' associated with water in CE: water, energy and materials. The application area is the Athens Plant Nursery, in the (water stressed) city of Athens, Greece. SM technology is in fact a mobile wastewater treatment unit in containers able to extract wastewater from local sewers, treat it directly and reuse at the point of demand even in urban environments with limited space. The unit consists of a membrane bioreactor unit (MBR) and a UV disinfection unit and produces high quality reclaimed water for irrigation and also for aquifer recharge during the winter. Furthermore, a short overview of the integrated nutrient and energy recovery subsystem is presented in order to conceptualise the holistic approach and circularity of the whole configuration. The SM technology demonstrates flexibility, scalability and replicability, which are important characteristics for innovation uptake within the emerging $\mathrm{CE}$ context and market.
\end{abstract}

Keywords: circular economy; sewer mining; wastewater reuse; decentralised wastewater treatment; replicability

\section{Introduction}

Within the past decade, increasing water consumption, water scarcity and climate change have affected global water security. Water resources are under stress as, according to the UN, it is estimated that by 2030 water shortages could reach $40 \%$ of total demand [1] and approximately half of the world's population could suffer from water stress [2]. Half million people are significantly affected as they live where water consumption surpasses the local water resources that lead to water scarcity at least one month each year [3]. By keeping the current situation - the discharge of untreated sewage, the partially treated wastewater from 
industry combined with unsustainable techniques used in agriculture-the degradation of water quality will continue to increase in the next decade, more intense in dry and poor countries [4]. This situation has led to an increased interest to explore alternative solutions to reduce waste and resource usage, the dominant behaviour of 'take-make-consumedispose', which assumes that resources are abundant, available and competitive to dispose of needs to be eliminated and. embrace 'circular economy' principles and technological innovation. It is therefore essential to design a new circular water management system that takes under consideration the different elements in the water cycle and maximises their efficient usage. Some measures that can be implemented, based on the principles of the circular economy (CE) model are to reuse by keeping water either within one system (closed loop) or redirecting it for use in other systems or communities.

Within the context of the urban water cycle, water reuse is a concept that is gaining traction and is considered an innovative way to address water scarcity [5]. Water reuse translates mainly into using treated wastewater (a waste) to supply (as a resource) a usually non-potable water use [6]. The centralised wastewater treatment plants are usually far away from the city centre and as a result the possibility of transporting the recovered water within the city requires high-cost constructions and energy-intensive processes which greatly increases the final water cost. Additionally, such configurations lack flexibility and autonomy of water resource in urban environments. On the other hand, decentralised technologies are in line with the circular economy approach by the in situ installation and also by eliminating the transmission costs [6].

A technology that can combine flexible and decentralised wastewater treatment as well as advanced treatment technologies is called sewer mining (SM). SM technology was originally pioneered in Australia in 2006 [7-10] and was first tested successfully in Greece through an FP7 project called Dessin in 2015 [6,11].

The present paper attempts to investigate further and more holistically the larger scale NextGen sewer mining hybrid MBR/UV system and its applicability in a real world urban environment, where wastewater is actually extracted from local sewers, treated at the point of demand and reused for irrigation in water-stressed green areas [12]. Thus, the current work focuses on presenting results that prove the high quality of the effluent water as well as the stability in the water quality produced by the system. Furthermore, in order to demonstrate the holistic approach of the solutions, the energy recovery unit along with the composting unit is briefly described in the scope of closing water energy material loops within a dense urban environment. The application area is the Athens Plant Nursery, in the water stressed city of Athens, Greece.

\section{Materials and Methods}

\subsection{General Description of the Circular Approach}

Athens is a city of 4 million citizens thus suffers from great urbanisation and emerging water scarcity issues. The Athens demo application is located in an area called Athens Plant Nursery, which is part of the Goudi Park, an area in the process of redevelopment and regeneration to become one of the key Metropolitan parks of the capital. The area, which lies in the heart of Athens and is illustrated in Figure 1, is a mixed-use area, comprising of urban green and urban agriculture spaces as well as administration and residential uses. The regeneration is an effort to boost both the local economy and improve quality of life for the citizens of the Attica Region.

The Athens Nursery covers an area of approximately 96 acres $/ 0.39 \mathrm{~km}^{2}, 40$ of which $\left(0.16 \mathrm{~km}^{2}\right)$ are used in the production, development and maintenance of the plants while the rest are used for general purposes such as administration building and offices of the Municipality of Athens. The Nursery supplies all urban parks and green spaces of Athens with plant material and uses potable water from Athens's Water Supply and Sewerage Company (EYDAP) for its irrigation. Furthermore, the pruning waste of the urban parks is accumulated in the Nursery, not treated, partly transferred in Athens landfill. About the use of fertilisers, these are bought from the market. With regards to the energy needs, 
the Nursery gets electrical energy from the urban network and for heating they use petrol oil. In this respect, the city seeks alternative water sources to achieve environmental, social and financial benefits to address the water scarcity matters through autonomous and decentralised water systems. Figure 2 presents the original linear situation in the Athens Plant Nursery in terms of water, energy and materials.

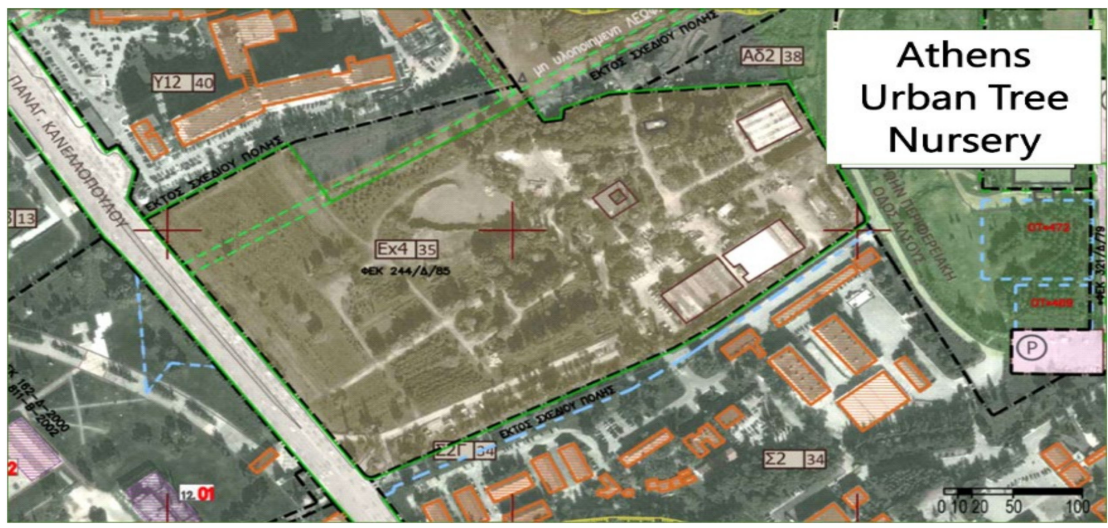

Figure 1. Area of the Athens Plant Nursery.

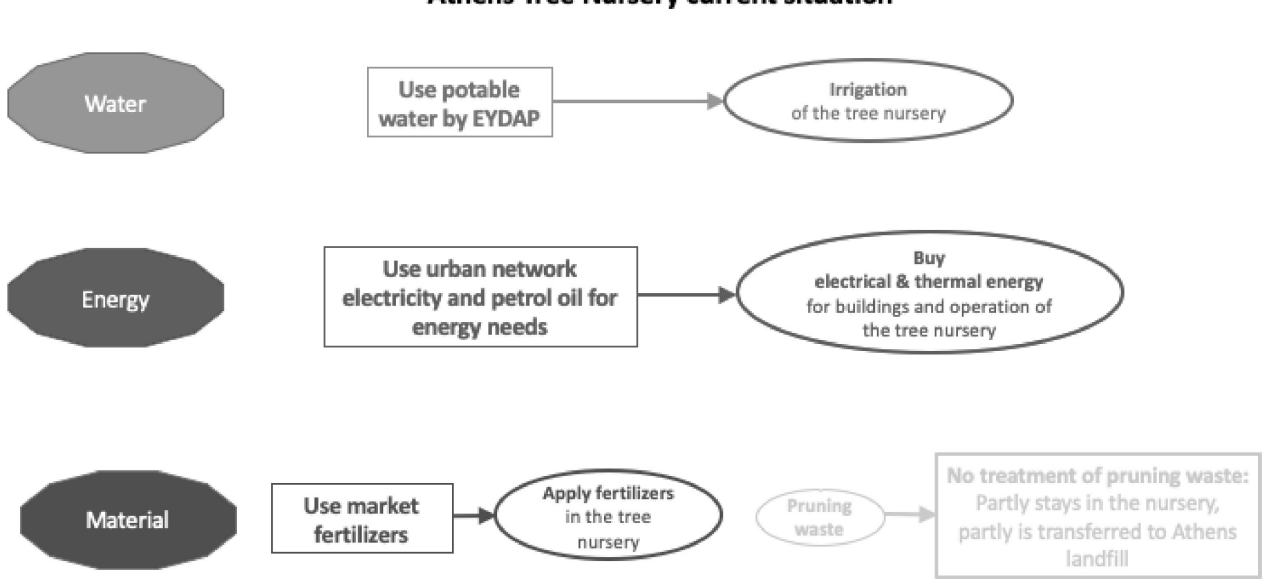

Figure 2. Linear baseline situation in Athens Plant Nursery in terms of water, energy and materials.

The Athens demo site hosts a circular, decentralised and innovative pilot system that tests all three aspects associated with CE: optimisation of water resources, nutrient mining and energy recovery and reuse practices. More specifically, as illustrated in Figure 3, wastewater is mined from a sewer (using sewer mining technology), treated at the point of demand through a mobile modular treatment unit that consists of a membrane bioreactor unit (MBR) along with a UV disinfection unit and reused directly for irrigation. In addition, the excess sludge from the treatment as well as appropriate organic waste streams from pruning are further treated via a rapid composting solution to produce nutrient-rich solid compost to be used as fertiliser for local (on-site) urban agriculture applications. Furthermore, energy recovery schemes directly from the sewer mining unit are tested to recover thermal energy for the configuration needs of the composting unit, thus, enhancing the circularity of the proposed approach.

In this paper a brief overview is provided in order to illustrate the concept and potential of the whole $\mathrm{CE}$ configuration. The focus is on examining the water-related element, that is the operation and performance of the SM unit for the two associated 'streams'. In the following section, the implemented sewer mining technology is presented in detail. 


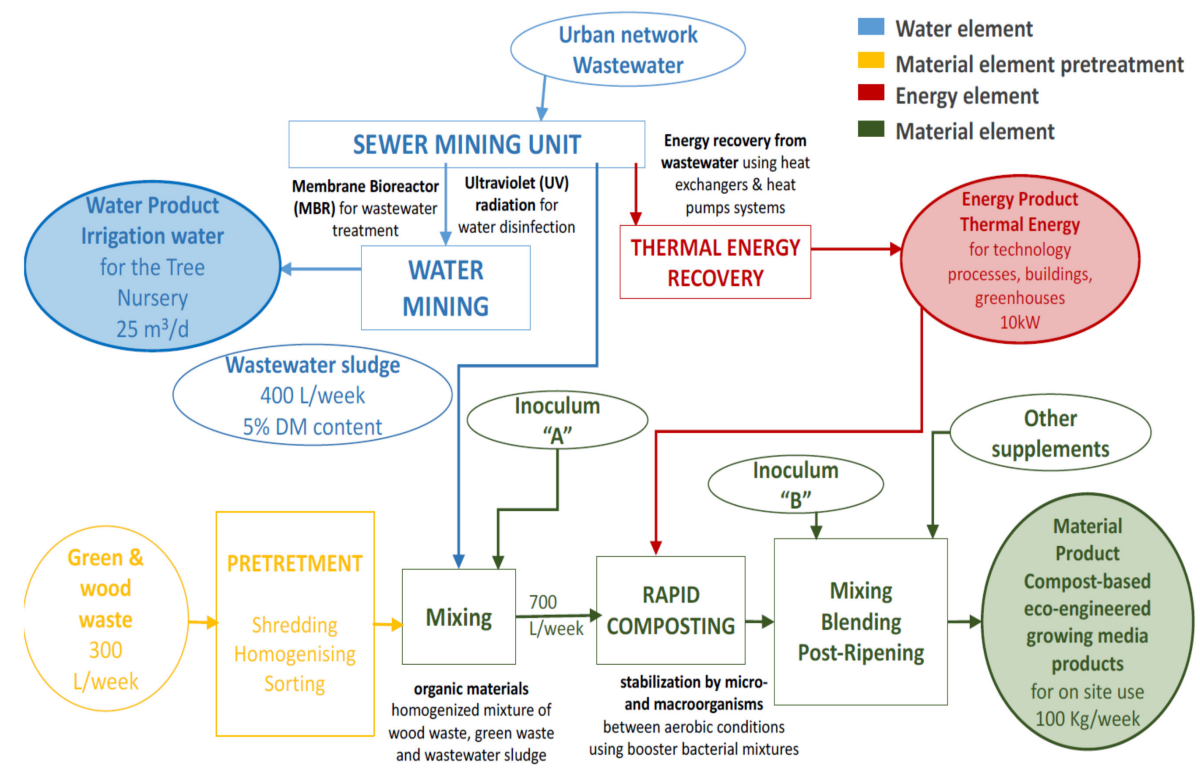

Figure 3. Circular economy approach for the Nursery in terms of water, energy and materials.

\subsection{Sewer Mining Technology}

\subsubsection{Concept and Set Up}

$\mathrm{SM}$ is a concept that is considered as an innovative way to address water scarcity in urban environments. This technology involves extracting untreated wastewater from the local sewers, treating it at the point of demand and producing fresh water. The effluent water is a high-quality water that can be used directly in a nearby area, for irrigation needs and for aquifer recharge during the winter, while waste by-products are returned to the mail sewerage system [13]. It is considered a sustainable management of water resources option to integrate into urban environment that suffer lack of water and green spaces [14-16]. A smaller pilot SM unit has been installed and set in operation in EYDAP's premises in Metamorphosis area in the context of the Dessin FP7 project since 2015 until now. This unit proved its efficiency and stability while produces effluent water suitable for any kind of use [11,13].

Membrane systems due to their mechanical configuration, have a high level of automation. Membrane bioreactors (MBR) are very efficient for removing the pathogens and also other parameters that are included into national and international legislation for wastewater irrigation. These parameters are emerging contaminants, heavy metals and priority substances [14-19]. These can simply be adapted to the whole CE system, to provide a completely automated system suited for decentralised wastewater treatment [13-15].

In NextGen's concept, a hybrid MBR/UV unit has been set in operation in April 2021. NextGen examines SM technology in a real environment with real extraction of wastewater through a prefabricated pumping station in the centre of Athens. The unit is far more advanced in terms of location, overall design with automatic operation and lower energy consumption. For installing the unit, the sewerage network was studied, in order to identify the optimum location for installing the equipment. In particular, the topography of the area, the adequacy of sewage flow as well as the quality characteristics of the influent were studied so that the SM unit and the pumping station are well designed according to the desired needs. The complete process and set up of the technology in the Athens Plant Nursery are illustrated in Figure 4. Raw sewage from the local city's network that passes through the Nursery flows by gravity into the tank of a prefabricated compact pumping station with a capacity of $25 \mathrm{~m}^{3} /$ day. 


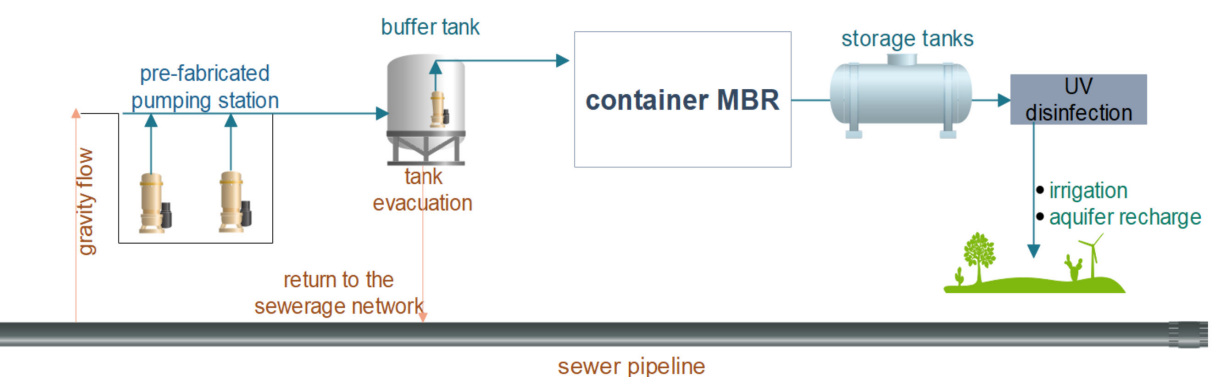

Figure 4. The Athens pilot configuration.

The treatment in the sewer mining unit comprises several processes taking place in a series of tanks as shown in Figure 5.

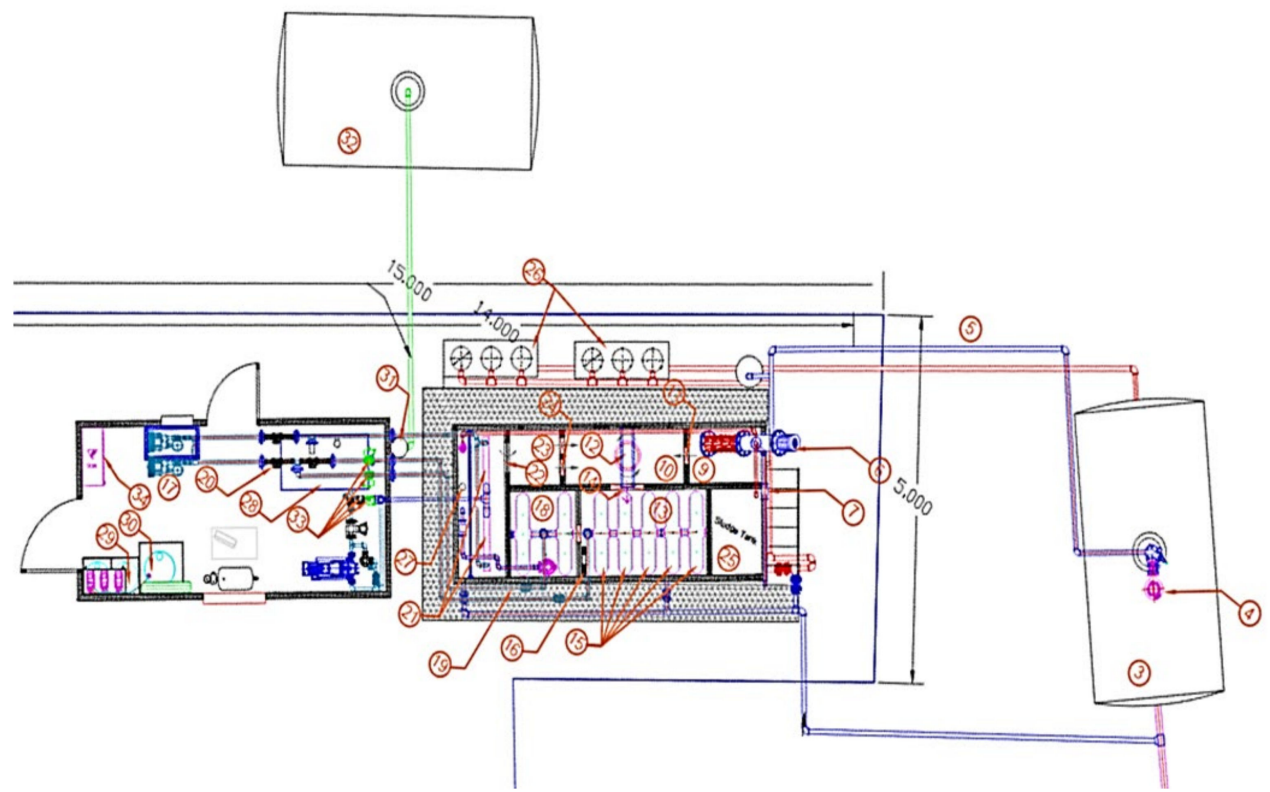

Figure 5. Top view of the hybrid MBR/UV system and the control room.

More specifically, the sewerage is extracted through two pumps that work alternately, from about four meters below the surface to fill in a buffer tank (3). Subsequently, the sewer mining unit is fed with wastewater through a submersible pump (4) installed inside the buffer tank. The raw sewage from the buffer tank is transferred through an inlet pipe (5) and screened while flowing through a continuously rotating self-cleaning screen filter (6) and its flow is constantly measured with an electromagnetic flowmeter. (7) The screenings (fine particulates) that are brushed away end up in a screenings bin (8) to be disposed or included in the compost produced later in the process.

In particular, the process starts when screened sewage is stored temporarily in a buffer tank (9) of filtered wastewater which communicates with a denitrification tank (10) through a bottom window (11). Inside the denitrification tank (10), anaerobic microorganisms turn nitrates to nitrogen gas which naturally leaves the system. A mixer (12) is also employed in the denitrification tank to help homogenise the mixture and keep the microorganisms in suspension and continuous contact with it. The denitrification tank communicates with the nitrification or aeration tank (13) through a bottom window (14). Inside the nitrification tank, aerobic microorganisms turn reduced nitrogen compounds (primarily ammonia) to nitrates. A constant dissolved oxygen concentration of $2-3 \mathrm{mg} / \mathrm{L}$ is maintained by supplying air through diffusers (15) to the aeration tank (13). A dissolved oxygen (16) meter is utilised to control the blowers' (17) air flow output using a variable frequency drive. 
There is an extra tank (18) that can function either as a second nitrification tank or a second denitrification tank depending on the systems' needs by turning on or off the air flow through the aeration tank air inlet pipe (19). The air flow pressure and temperature are monitored constantly (20).

Subsequently, the biologically treated wastewater is transferred to the membrane tank with a constant flowrate of $5 \mathrm{~m}^{3} / \mathrm{h}$. Membrane modules (21) composed of $80 \mathrm{~m}^{2}$ of hollow fibres can produce about $1 \mathrm{~m}^{3} / \mathrm{h}$ of permeate water so the remaining $4 \mathrm{~m}^{3} / \mathrm{h}$ overflows through the tanks top window (22) to the deoxygenation tank (23) where anaerobic conditions are met before the mixture enters the denitrification tank once again through a bottom window (24).

An amount of the excess sludge that is produced is transferred to the thickening tank (25) and then it flows to the dewatering bag filters (26) to be thickened and used for the compost product. The mixed liquor suspended solids (MLSS) value is measured (27) online and is kept constant between 10.000 and $11.000 \mathrm{mg} / \mathrm{L}$.

The permeate produced in the membranes is pumped into the backflush tank (28) to be used during the backflush sequence. During this sequence, $1.4 \mathrm{~m}^{3}$ of permeate is pumped inversely from the backflush tank (28) through the inside of the membranes to clean their surface and dissolve the cake layer that is formed. The ultrafiltration membranes (21) achieve a better filtration of the biologically treated wastewater, removing all suspended solids, colloids bacteria and viruses. Additionally, a chemically enhanced backflush sequence occurs once per day, during which, sodium hypochlorite (29) and citric acid (30)solutions are added to the backflush sequence. Then, the permeate overflows and passes through the UV disinfection unit (31) and the final disinfected product flows naturally toward irrigation storage tank (32).

The whole process is fully monitored through specific sensors (tanks level, $\mathrm{pH}$ meters, MLSS sensors of the HACH Lange company, dissolved oxygen probes, etc.,) and is automated using pneumatic actuated valves (33) that are controlled by a PLC unit (34). An external overview of the sewer mining unit (on the right) and the control room (on the left) are illustrated in Figure 6.

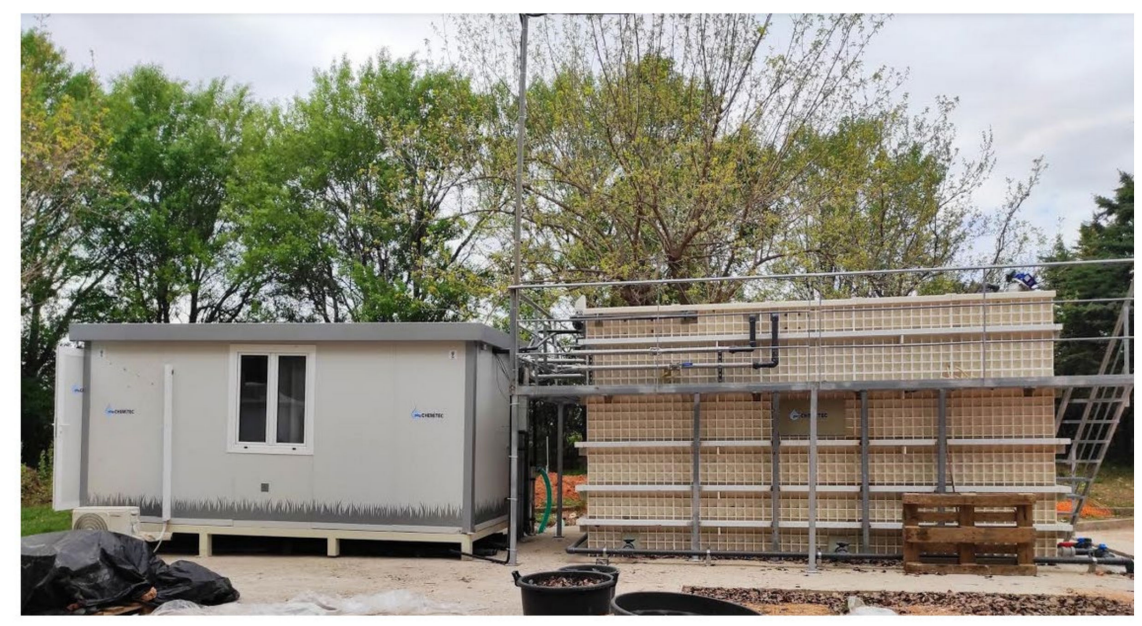

Figure 6. Overview of the sewer mining unit and the control room.

\subsubsection{Experimental Design}

The monitoring process consists of sampling from five (5) distinct points of the pilot unit. Specifically, regarding conventional parameters (COD, TSS, TN, etc.) composite samples were collected, twice per week from filtered inlet, membrane tank, denitrification tank, permeate tank and after UV disinfection. The parameters monitored were: COD, BOD, $\mathrm{TP}, \mathrm{TN}, \mathrm{NH}_{4}-\mathrm{N}^{+}, \mathrm{NO}_{3}-\mathrm{N}^{-}, \mathrm{TC}, \mathrm{EC}, \mathrm{pH}$, conductivity, dissolved oxygen and transmembrane pressure (TMP). All analyses occurred regarding Standard Methods (APHA, 2017). 


\subsubsection{Operating Parameters}

The current evaluation and results derive from 4.5 months of full operation of the SM unit (mid-April-August 2021). During this period, the temperature at the time period examined ranged from 18 to $25{ }^{\circ} \mathrm{C}$. The capacity of the unit was set to $25 \mathrm{~m}^{3}$ of treated water per day, even though it has been designed to be able to reach $100 \mathrm{~m}^{3} /$ day. The concentration of mixed liquor suspended solids (MLSS) in the MBR tank was controlled roughly at $10 \mathrm{~g} / \mathrm{L}$ with daily extraction of excess sludge, while the same variable inside the anoxic and aeration tank had a value of about $8 \mathrm{~g} / \mathrm{L}$. Moreover, the sludge retention time (SRT) was set to 20 days.

An operation cycle of MBR involved a 10-min filtration and a 1-min backflushing mode to preserve the membrane's permeability. The maintenance cycles include one oxidising cleaning per day and one acid maintenance per week. Table 1 provides information about the membrane that has been installed in the system.

Table 1. Membrane characteristics.

\begin{tabular}{cc}
\hline Manufacturer & KOCH \\
\hline Membrane type & Hollow Fiber \\
Membrane model & PSH 41 \\
Pore size & $0,03 \mu \mathrm{m}$ \\
Membrane surface & $\left(2 \times 41 \mathrm{~m}^{2}\right)$ \\
Material & Proprietary PVDF \\
Specific Air Demand based on membrane area (SADm) & $0.36 \mathrm{~m}^{3}$ air $/ \mathrm{m}^{2}$ membrane area $/ \mathrm{h}$ \\
\hline
\end{tabular}

The last stage of treatment for the safe disposal of treated wastewater is a UV disinfection unit. Table 2 provides information about the UV disinfection unit.

Table 2. UV unit characteristics.

\begin{tabular}{cc}
\hline Manufacturer & S.I.T.A. Srl (Societa' Italiana Trattamento Acque) \\
\hline Model & 440 LCD RM model \\
Material & AISI 316L \\
Max Flow rate & $60 \mathrm{~L} / \mathrm{min}$ \\
No. of UV-C lamps & 1 \\
Life of lamps (around) & $9000 \mathrm{~h}$ \\
UV-C Dose & $>300 \mathrm{~J} / \mathrm{m} 2$ \\
Working pressure (max.) & $9 \mathrm{bar}$ \\
\hline
\end{tabular}

To control the quality of the process and of the effluent, a series of online sensors was adjusted in several key points of the unit, which provides continuous information about the integrity of the operation. More specifically, an MLSS sensor and a $\mathrm{pH}$ sensor were installed in the membrane tank, two DO sensors in the aeration tank and in the denitrification tank and a turbidity sensor in the permeate tank.

Apart from using sensors a series of lab tests provide feedback for the unit and many of them are used for cross validation with the sensor measurements, thus providing feedback on the status of the sensors. The laboratory analysis takes place twice a week and includes measurements of COD, BOD, TP, TN, $\mathrm{NH}_{4}-\mathrm{N}^{+}, \mathrm{NO}_{3}-\mathrm{N}, \mathrm{TC}, \mathrm{EC}, \mathrm{MLSS}$, mixed liquor volatile suspended solids, diluted sludge volume index (DSVI), biochemical oxygen demand $\left(\mathrm{BOD}_{5}\right)$, total phosphorus $(\mathrm{TP})$, total nitrogen $(\mathrm{TN}), \mathrm{NH}_{4}-\mathrm{N}, \mathrm{NO}_{3}-\mathrm{N}$, total coliforms (TC), faecal coliforms (FC) and Escherichia coli (EC). Table 3 summarises the operational parameters of the system. 
Table 3. Operational parameters of the system.

\begin{tabular}{ccc}
\hline Parameters & PHASE 1 Start Up & PHASE 2 Steady State Conditions \\
\hline Days of operation & 40 & $41-140$ \\
Operating temperature & $18-23$ & $18-25$ \\
Q $\left(\mathrm{L} \cdot \mathrm{d}^{-1}\right)$ & 25 & 25 \\
$\mathrm{HRT}(\mathrm{d})$ & 2 & 1 \\
$\mathrm{SRT}(\mathrm{d})$ & $\infty$ & 20 \\
Flux $\left(\mathrm{L} / \mathrm{m}^{2} \mathrm{~h}\right)$ & $1.6 \pm 0.2$ & $3.3 \pm 0.4$ \\
OLR $\left(\mathrm{KgCOD} / \mathrm{m}^{3} / \mathrm{d}\right)$ & $0.225 \pm 0.03$ & $0.45 \pm 0.05$ \\
Waste Activated Sludge $\left(\mathrm{L} \cdot \mathrm{d}^{-1}\right)$ & - & 1.6 \\
\hline
\end{tabular}

\subsubsection{Cost Parameters}

Regarding the SM unit's cost, the total capital cost of produced water was calculated to be $0.36 € / \mathrm{m}^{3}$, while the operational cost amounts to $0.5 € / \mathrm{m}^{3}$, which produces a quite moderate total cost of $0.86 € / \mathrm{m}^{3}$ of produced water [11].

The economic evaluation of the sewer mining technology demonstrated in the Athens Urban Tree Nursery showed that in general SM technology is a viable and profitable scheme and can be an interesting alternative water source to more conventional options (such as potable water from the central system). The Nursery's SM investment allows for significant cost reduction compared to the current situation. A complete cost-benefit analysis that takes into consideration the sum of the environment, social and economic cost-benefits, is expected to make the SM technology even more attractive [20].

\subsection{Production of Compost and Energy Recovery Technologies}

With regards to the other two 'streams', energy and materials, a brief overview of the basic concepts and potential is provided in order to illustrate that the sewer mining technology is part of a more integrated and circular approach, aiming at closing the respective loops within a dense urban environment. A flow scheme of the technology is illustrated in Figure 7.

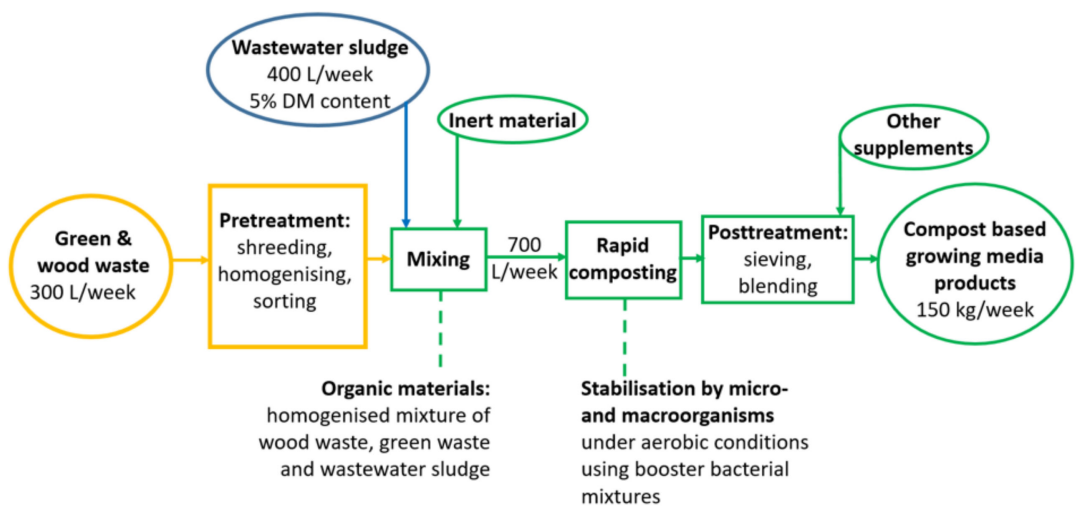

Figure 7. Flow scheme of the technology.

With regards to the material, significant amounts of pruning materials accumulated in the Athens Plant Nursery until now remain untapped resources. The excess sludge produced from the sewer mining unit along with the green and wood waste goes through a rapid composting process to produce on-site fertiliser.

The rapid composting technology is illustrated in Figure 8 and follows the specific steps. First, the sludge is thickened through dewatering in bag filters to a dry solid content of approximately $5 \%$. Meanwhile, the wood and green waste is shredded, homogenised and sorted through a specific sieve to get a fraction of about 2-5 $\mathrm{mm}$. In a mixing unit, homogenised wood and green waste are mixed with the thickened excess sludge and an inert filling material consisting of shredded wood of $2-5 \mathrm{~cm}$ size. The mixer continuously 
rotates the entire contents of the reactor. Approximately $700 \mathrm{~L} /$ per week are incubated in the rapid composting unit at mostly aerobic conditions due to continuous air supply by the connected blower. At a temperature between 50 and $70{ }^{\circ} \mathrm{C}$, aerobic microorganisms convert approximately 20-30\% of the volatile organic material to $\mathrm{CO}_{2}$ and water and thus, stabilise the material. Due to mixing, aeration and high temperature, the thermophilic composting process is significantly accelerated compared to the conventional process. The retention time in the composting unit ranges between 10 and 15 days depending on the input raw material.

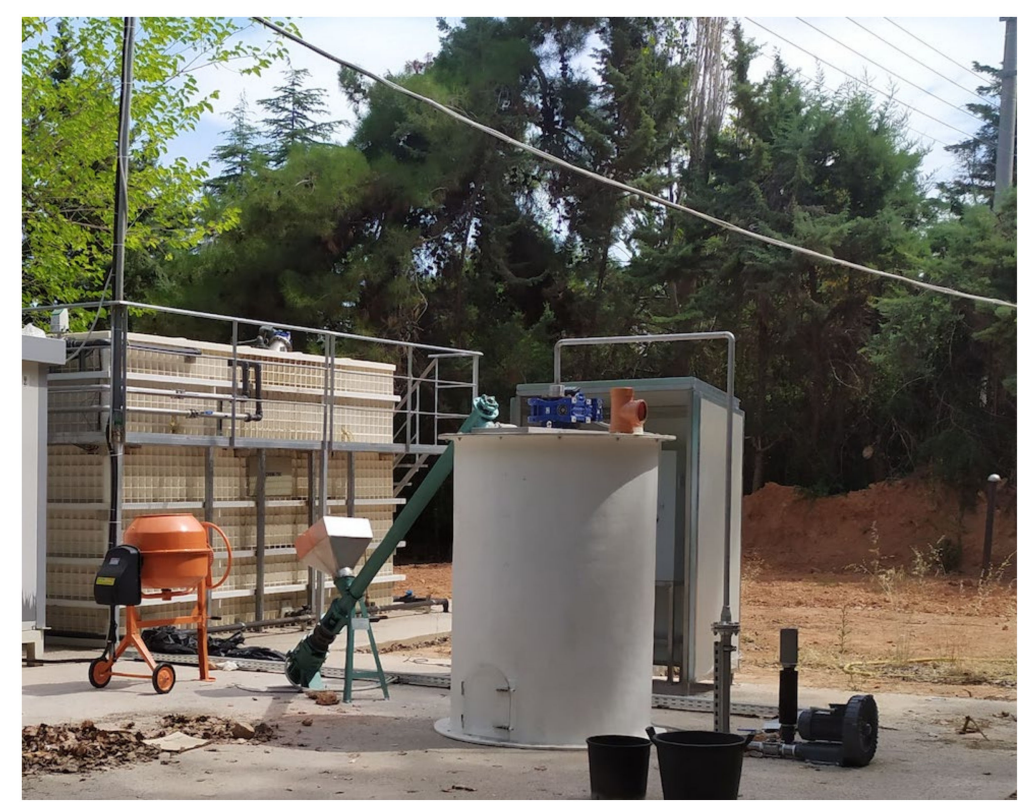

Figure 8. Layout of the rapid composting bioreactor (RCB).

The output is a compost-based growing media product with output rate of around 150-180 kg per week. Optimum oxygen concentration, temperature, humidity and mixing intensity are monitored by means of sensors and microprocessor. The output compost goes through a sieve to get back the inert filling material. It should be noted that the heavy metals and trace organics in the excess sludge and in the finished product are regularly monitored, in order to ensure a concentration which complies with the existing regulations for the use of the end product. The composting bioreactors system is illustrated in Figure 8.

With regards to the energy recovery unit this consists of a heat exchanger and heat pump system that recovers thermal energy from the wastewater to be reused for the technological processes of the compost production unit.

The operation and results of the compost production and the energy recovery units are not in the scope of the present paper and are only briefly described as additional elements of the SM unit that comprise the whole CE configuration.

\section{Results and Discussion}

\subsection{Athens Demo Case Start-Up}

The unit started its full operation in mid-April 2021. The previous 2 months, the unit was working with clean water for assessing the automations and testing the performance of the pumping station and the hybrid MBR/UV pilot system. The whole performance of the unit and of the pumping station has shown great stability. The hybrid MBR/UV had a start period of approximately 5 weeks. Figure 9 illustrates the start-up period of the unit along with some period of early steady state conditions. It is evident that even during the start-up period the removal rates are higher than $90 \%$ which shows that the MBR technology is a very safe technology to use due to the great stability it provides. 


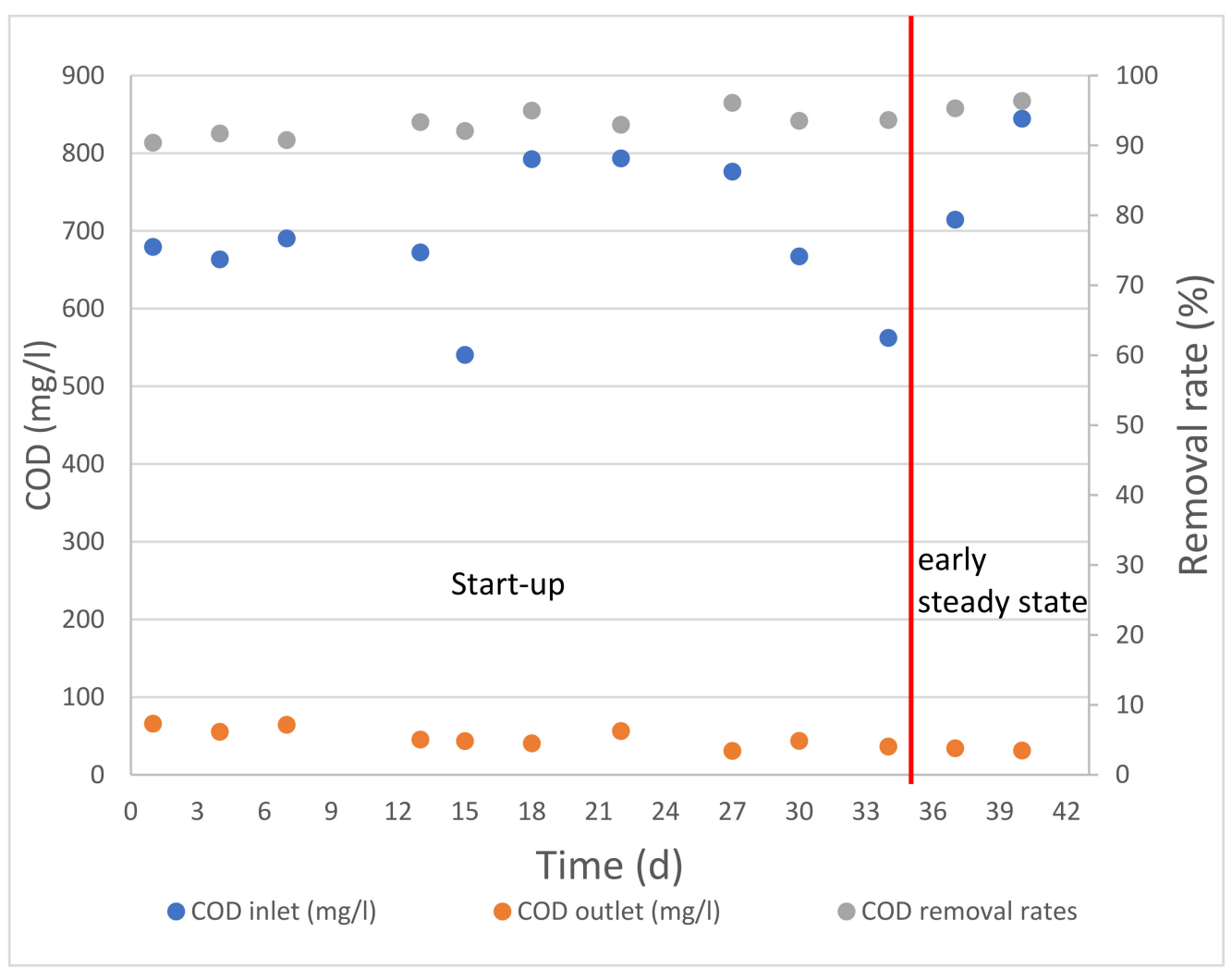

Figure 9. Start-up period.

Figure 9 illustrates the start-up of the unit regarding COD removal. Concentrations of the raw sewage shows many fluctuations but that does not affect the effluent COD concentrations. Even during start-up the effluent COD had concentrations of $60 \mathrm{mg} / \mathrm{L}$ which then decreased further and stabilised at the average value of $34 \mathrm{mg} / \mathrm{L}$. The first evidence of nitrification appeared at around day 33 when a sharp increase was observed in the effluent nitrate concentrations from near detection limit to higher than $15 \mathrm{mg} / \mathrm{L}$ which coincided with sharp decreases in ammonia concentrations.

\subsection{Athens Demo Case Overall Performance}

After the start-up, a monitoring plan was implemented to regularly collect and analyse a series of raw and treated wastewater samples. Whole MBR/UV operation showed great stability in terms of constant operation as well as effluent water quality. In combination with our previous experience of the Dessin's unit since 2015 [21], NextGen's unit seems an even more advanced solution for implementing decentralised wastewater treatment water reuse schemes at the point of demand. The added value of this particular unit is the fact that it addresses real world water scarcity issues in a dense urban environment, by transforming treated wastewater (a waste) into supply (a resource). Figures 10 and 11 depict the MBR performance for the whole-time operation in terms of TSS and $\mathrm{NH}_{4}-\mathrm{N}$ removal respectively. More specifically, Figure 10 shows the TSS of the inlet and outlet, the MLSS concentration inside the MBR tank as well as the online measurements of the installed probe. It is evident that TSS concentrations of the effluent reach zero while the installed probe provide data that fit with the laboratory measurements. Figure 11 illustrates the concentrations of the $\mathrm{NH}_{4}-\mathrm{N}$ of the inlet and the outlet. It is shown that after the 33rd day the nitrification started while the effluent concentrations of ammoniacal nitrogen's concentrations started reaching zero. Table 4 illustrates the aggregated results for the quality characteristics of the Hybrid MBR/UV effluent of the experimental system along with the limit values as set in the Greek National legislation regarding wastewater reuse for unrestricted irrigation and urban use (JMD 145116/2011). Figure 10 shows two time 
periods. The start-up period and the period of steady state conditions. The period of steady state is defined as the period with constant MLSS concentration, steady removal rates and initiation of nitrification.

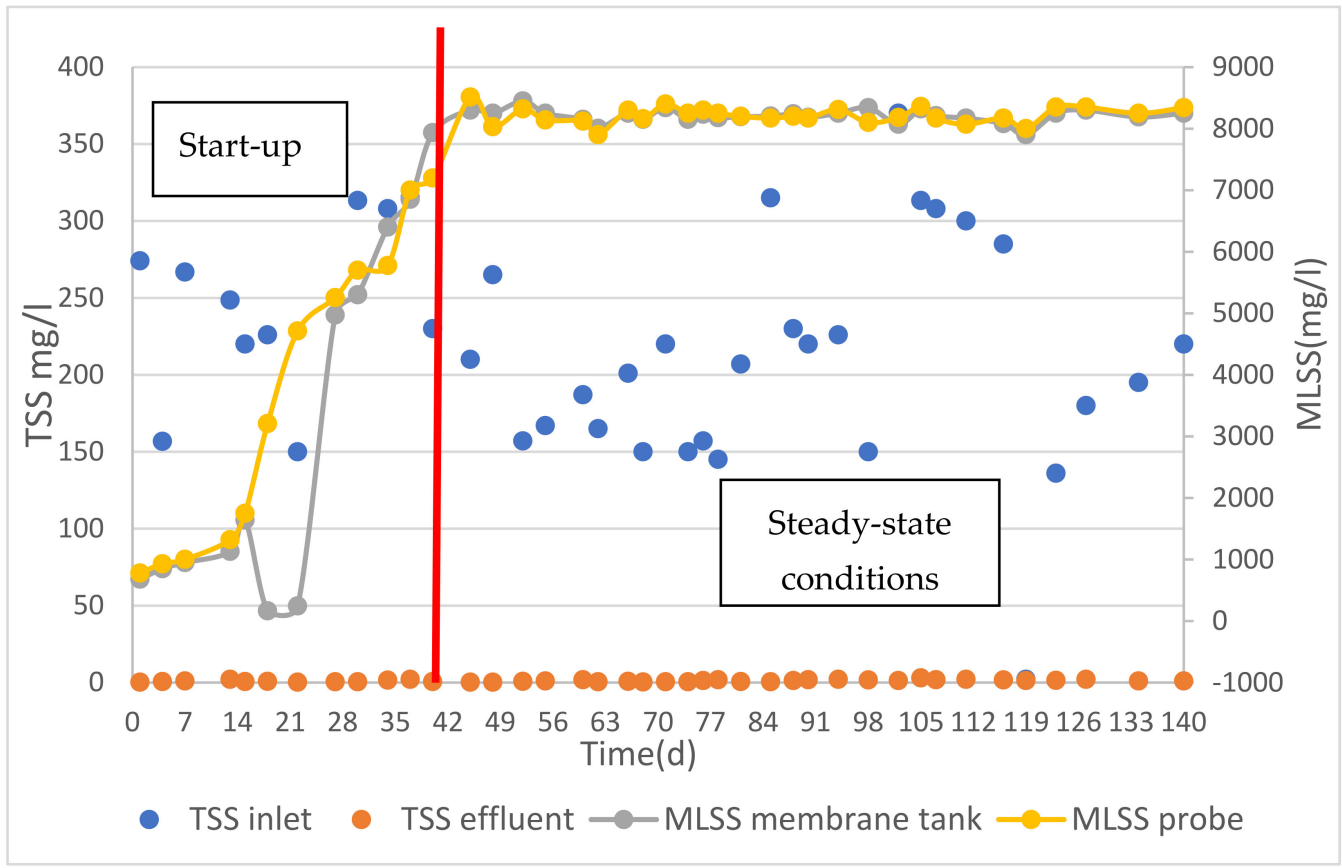

Figure 10. MBR performance in terms of TSS removal.

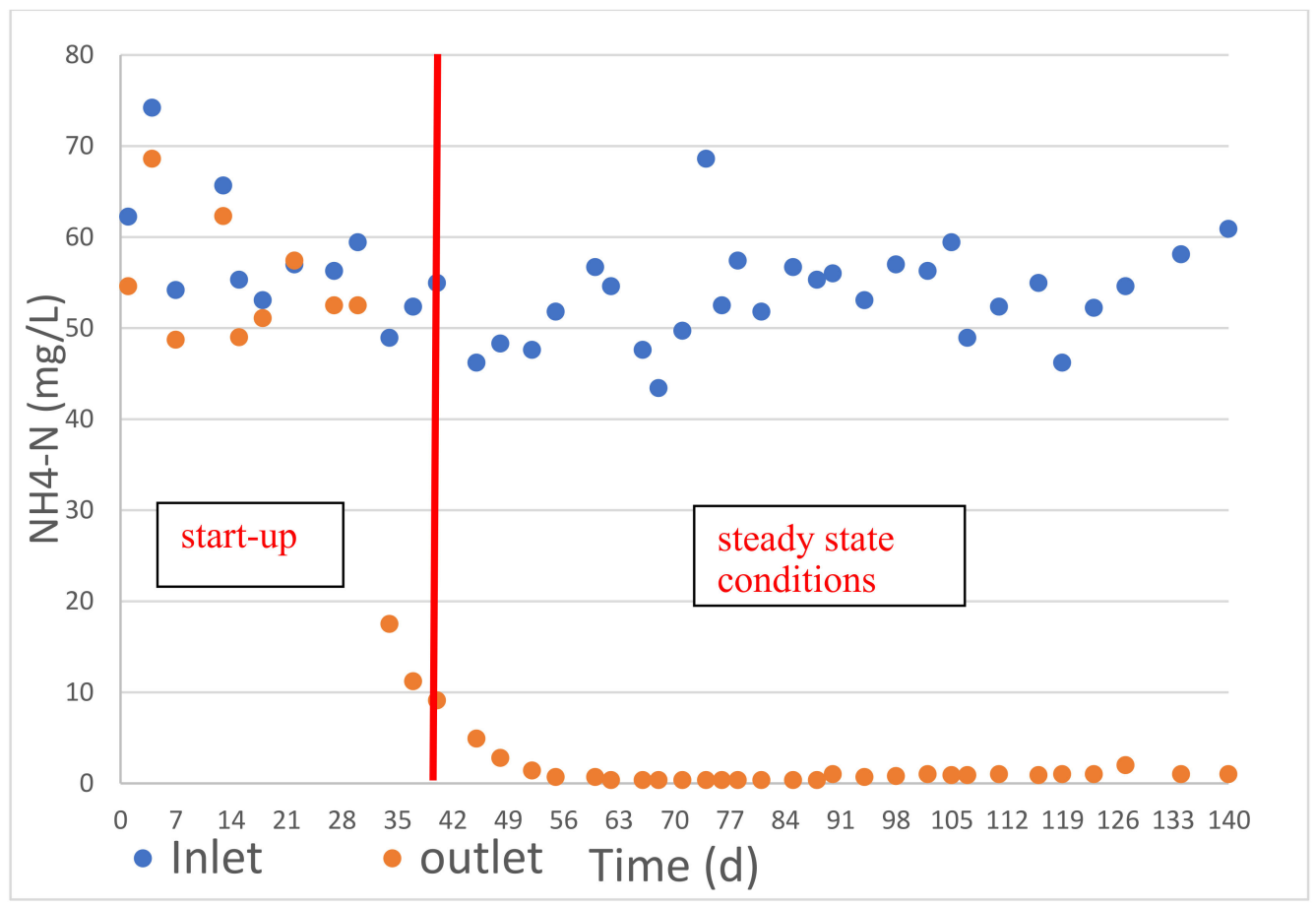

Figure 11. MBR performance in terms of $\mathrm{NH}_{4}-\mathrm{N}$ removal. 
Table 4. Performance of the Hybrid MBR/UV pilot system (concentrations in mg/L, TC, FC, EC in cfu/100 mL, turbidity in NTU, conductivity in $\mu \mathrm{S} / \mathrm{cm})$.

\begin{tabular}{|c|c|c|c|}
\hline Parameters & Influent $^{1}$ & Effluent after UV Disinfection & Legislation Limits $^{2}$ \\
\hline TSS & $253 \pm 97^{3}$ & $\leq 2$ for $80 \%$ of samples & $\begin{array}{l}\leq 2 \text { for } 80 \% \text { of samples } 5 \\
\leq 10 \text { for } 80 \% \text { of samples }\end{array}$ \\
\hline $\mathrm{BOD}_{5}$ & $216 \pm 64^{3}$ & $\begin{array}{c}9 \text { (average) } \\
9.6 \text { for } 80 \% \text { of samples }\end{array}$ & $\leq 10$ for $80 \%$ of samples 4,5 \\
\hline CODt & $695 \pm 97^{3}$ & $34 \pm 5^{3}$ & \\
\hline $\mathrm{TN}$ & 81 (average) & 18 (average) & $\leq 15^{4,5}$ \\
\hline $\mathrm{NH}_{4}-\mathrm{N}$ & $5 \pm 3^{3}$ & $0.25 \pm 0.3^{3}$ & $\leq 2^{4,5}$ \\
\hline $\mathrm{TP}$ & $10 \pm 1.4^{3}$ & $5.9 \pm 1^{3}$ & - \\
\hline Turbidity & - & 2 (median) & $\leq 2($ median $) 4,5$ \\
\hline Conductivity & $1109 \pm 75^{3}$ & $1067 \pm 170^{3}$ & - \\
\hline $\mathrm{pH}$ & $7.1 \pm 0.1^{3}$ & $7.5 \pm 0.3^{3}$ & - \\
\hline $\mathrm{TC}$ & $>10^{6}$ & $\begin{array}{l}2 \text { for } 80 \% \text { of samples } \\
9 \text { for } 95 \% \text { of samples }\end{array}$ & $\begin{array}{l}\leq 2 \text { for } 80 \% \text { of samples } 5 \\
\leq 20 \text { for } 95 \% \text { of samples } 5\end{array}$ \\
\hline FC & $>10^{6}$ & $\leq 3$ & - \\
\hline EC & $>10^{6}$ & $\begin{array}{l}\leq 3 \text { for } 80 \% \text { of samples } \\
\leq 3 \text { for } 95 \% \text { of samples }\end{array}$ & $\begin{array}{l}\leq 5 \text { for } 80 \% \text { of samples } 4 \\
\leq 50 \text { for } 95 \% \text { of samples } 4\end{array}$ \\
\hline
\end{tabular}

${ }^{1}$ Refer to filtered wastewater; ${ }^{2}$ refer to the Greek legislation regarding wastewater reuse (Joint Ministerial Decision 354/8-3-2011); ${ }^{3}$ average \pm standard deviation; ${ }^{4}$ refer to the limit values set in the Greek legislation for wastewater reuse for unrestricted irrigation and/or industrial reuse; ${ }^{5}$ refer to the limit values set in the Greek legislation for urban reuse and/or groundwater recharge; ${ }^{6}$ refer to the limit value set in the Greek legislation for every type of reuse for WWTPs with a population equivalent greater than 100,000.

It is evident that the MBR effluent characteristics lie within the limits set in the Greek wastewater reuse legislation for unrestricted irrigation and urban use. Its EC and FC contents are minimal, while its TC content is low. There are some values for total nitrogen and ammoniacal nitrogen during the start-up that are higher than the limits set in the National Legislation. This is due to nitrification-denitrification which is a slow process to start. Therefore, it is anticipated that to achieve effluent characteristics for all the parameters, the system needs to find steady-state conditions.

The aggregated results of Table 4 confirm what was already concluded from our previous experience that the Hybrid MBR/UV unit manages the removal of the organic content and also with high rates of nitrification. The microbial load is also completely removed after the UV disinfection unit. Table 5 presents the UV performance by providing microbial data before (MBR tank) and after the UV disinfection.

Table 5. UV performance (concentrations in $\mathrm{cfu} / 100 \mathrm{~mL}$ ).

\begin{tabular}{ccc}
\hline Parameters & MBR Effluent & After UV Disinfection \\
\hline TC & $10,525 \pm 2874$ & $\begin{array}{l}2 \text { for } 80 \% \text { of samples } \\
9 \text { for } 95 \% \text { of samples }\end{array}$ \\
\hline FC & $21 \pm 18$ & $\leq 3$ \\
\hline EC & $3.75 \pm 0.5$ & $\begin{array}{l}\leq 3 \text { for } 80 \% \text { of samples } \\
\leq 3 \text { for } 95 \% \text { of samples }\end{array}$ \\
\hline
\end{tabular}

UV disinfection unit shows great performance. The dose of $60 \mathrm{~L} / \mathrm{min}$ is enough to remove all pathogens and produce safe water for any kind of reuse as it meets even the strictest criteria.

Except for the start-up period, the total operation of the system shows great stability. The COD removal rates are kept higher than $90 \%$ and the filtration performance was very 
stable. The values of the transmembrane pressure have been kept low with an average value at around 135 mbar. Dissolved oxygen (DO) was kept in the aeration tank at values greater than $2 \mathrm{mg} / \mathrm{L}$ during the whole time of operation. The combination of the aeration tank along with the MBR filtration was very successful for the removal of all the biodegradable COD but also all suspended solids as they cannot pass through the pores of the membrane. Its automations enable it to operate autonomously without the need for daily monitoring.

The presented characteristics of the effluent water, in combination with the compact nature of the pilot unit that neither requires other than the existing infrastructures nor plenty space, make the hybrid unit an ideal solution for the Athens Plant Nursery but also overall for municipalities suffering from water scarcity.

\section{Conclusions}

This paper focuses on the demonstration of a distributed circular solution addressing the real-world challenge of providing autonomous, decentralised resource recovery in water scarce cities and hence 'climate-proof' non-potable water supplies (such as urban green space irrigation) against the uncertainty [22] that is necessarily associated with water supply from natural water sources and related hydroclimatic changes.

The implementation of a sewer mining unit that produces high-quality reclaimed water for urban green irrigation at the point of demand is proven to address resource efficiency issues in a circular economy context.

According to the findings of this study, it is concluded that the application of SM technology through the implementation of a prefabricated pumping station along with an on-site compact hybrid MBR/UV treatment system allows to produce water of excellent quality that meets all the national and international criteria set regarding wastewater reclamation for urban reuse. The system presented very satisfactory operational stability and great performance. The elimination of organic carbon and pathogenic content was complete. The filtration process through the MBR managed the reduction of pathogens without any addition of chemicals, thus avoiding the production of secondary pollutants. TMP remained steady at low values, proving that the combination of backflushing with maintenance cleaning was very effective. Additionally, the UV disinfection unit showed great performance.

Sewer mining, due to the limited space required for installation and its decentralised form, can be installed in situ, and therefore is closer to the circular economy concept. Additionally, the SM technology is designed in an advanced and flexible design manner as it also includes the identification of the optimum sewage network location for extracting wastewater, the design and construction of a compact system placed in a container right at the point of demand and the energy-efficient prefabricated pumping system. Therefore, a variety of benefits are anticipated: e.g., the overtaxed wastewater systems can be relieved, water and wastewater infrastructure costs can be trimmed, energy and chemical use is reduced and potable water is saved. Hence, this research provides proof of pilot operation of an innovative solution, in which a compact mobile wastewater treatment system is able to extract wastewater from local sewers, treat it directly and reuse at the point of demand. Furthermore, the innovation of this technology lies in the fact that, in terms of treatment, it is a very efficient and stable system, it requires limited space thus has a small footprint and it transforms treated wastewater (a waste) into supply (a resource). Subsequently, it seems ideal for implementing decentralised wastewater treatment and water reuse schemes to address real-world water scarcity issues in a dense urban environment.

These technologies along with the whole pumping station engineering design and the UV disinfection unit are implemented and tested for the first time in Greece in a realworld application and the results aim to serve as a step towards more flexible, expandable, scalable and replicable CE solutions.

Author Contributions: Conceptualisation, C.M., C.L. and E.L.; methodology, C.M. and C.L.; startup, testing and operation of the SM unit, N.T. (Nikolaos Tazes); sampling and analysis, G.K., N.T. (Nikolaos Tsalas); data processing, A.P., S.S. and K.M.; writing-original draft preparation, A.P. and 
K.M.; writing-review and editing, A.P. and K.M.; supervision, C.M. All authors have read and agreed to the published version of the manuscript.

Funding: This research received no external funding.

Institutional Review Board Statement: Not applicable.

Informed Consent Statement: Not applicable.

Data Availability Statement: The data presented in this study are available on request from the corresponding author. The data are not publicly available in a specific link due to fact that there is an ongoing process of sampling and laboratory analysis in order to compile a database.

Acknowledgments: The research leading to these results has received funding from the European Union's Horizon 2020 under grant agreement no 776541, for the research project NextGen "Towards a next generation of water systems and services for the circular economy". The research and its conclusions reflect only the views of the authors, and the European Union is not liable for any use that may be made of the information contained herein.

Conflicts of Interest: The authors declare no conflict of interest. The funders had no role in the design of the study; in the collection, analyses, or interpretation of data; in the writing of the manuscript, or in the decision to publish the results.

\section{References}

1. World Economic Forum-Home. Available online: http://www3.weforum.org/maintenance/public.html (accessed on 29 January 2020).

2. Zarei, M. Wastewater resources management for energy recovery from circular economy perspective. Water-Energy Nexus 2020, 3, 170-185. [CrossRef]

3. World Water Assessment Programme (WWAP). The United Nations World Water Development Report 2017-Wastewater: The Untapped Resource; UNESCO: Paris, France, 2017. Available online: http://unesdoc.unesco.org/images/0024/002471/247153e.pdf (accessed on 3 September 2021).

4. Environmental Performance Index; Yale University. 2018. Available online: https://epi.yale.edu/epi-results/2020/component/ epi (accessed on 3 September 2021).

5. Angelakis, A.N.; Gikas, P. Water Reuse: Overview of Current Practices and Trends in the World with Emphasis on EU States. Water Util. J. 2014, 8, 67-78.

6. Makropoulos, C.; Rozos, E.; Tsoukalas, I.; Plevri, A.; Karakatsanis, G.; Karagiannidis, L.; Makri, E.; Lioumis, C.; Noutsopoulos, C.; Mamais, D.; et al. Sewer-mining: A water reuse option supporting circular economy, public service provision and entrepreneurship. J. Environ. Manag. 2017, 216, 285-298. [CrossRef] [PubMed]

7. Sydney Water Sewer Mining. How to Set up a Sewer Mining Scheme. 2019. Available online: http://www.waterforlife.nsw.gov. au/recycling (accessed on 3 September 2021).

8. Chanan, A.; Woods, P. Introducing total water cycle management in Sydney: A Kogarah Council initiative. Desalination 2006, 187, 11-16. [CrossRef]

9. Xie, M.; Nghiem, L.D.; Price, W.E.; Elimelech, M. A Forward Osmosis-Membrane Distillation Hybrid Process for Direct Sewer Mining: System Performance and Limitations. Environ. Sci. Technol. 2013, 47, 13486-13493. [CrossRef] [PubMed]

10. Sewer Mining Technology Trial at Flemington Racecourse. Smart Water Fund. Project Library. Available online: https:// waterportal.com.au/swf/projects/item/39-sewer-mining-technology-trial-at-flemington-racecourse (accessed on 30 August 2021).

11. Plevri, A.; Mamais, D.; Noutsopoulos, C.; Makropoulos, C.; Andreadakis, A.; Rippis, K.; Smeti, E.; Lytras, E.; Lioumis, C. Promoting on-site urban wastewater reuse through MBR-RO treatment. Desalination Water Treat. 2017, 91, 2-11. [CrossRef]

12. Water \& Circular Economy-NextGen Water. Available online: https://nextgenwater.eu/water-circular-economy/ (accessed on 29 January 2020).

13. Plevri, A.; Noutsopoulos, C.; Mamais, D.; Makropoulos, C.; Andreadakis, A.; Lytras, E.; Samios, S. Priority pollutants and other micropollutants removal in an MBR-RO wastewater treatment system. Desalin. Water Treat. 2018, 127, 121-131. [CrossRef]

14. Norton-Brandão, D.; Scherrenberg, S.M.; van Lier, J.B. Reclamation of used urban waters for irrigation purposes-A review of treatment technologies. J. Environ. Manag. 2013, 122, 85-98. [CrossRef] [PubMed]

15. Le-Minh, N.; Coleman, H.M.; Khan, S.J.; Van Luer, Y.; Trang, T.T.T.; Watkins, G.; Stuetz, R.M. The application of membrane bioreactors as decentralised systems for removal of endocrine disrupting chemicals and pharmaceuticals. Water Sci. Technol. 2010, 61, 1081-1088. [CrossRef] [PubMed]

16. Arévalo, J.; Ruiz, L.; Pérez, J.; Moreno, B.; Gómez, M. Removal performance of heavy metals in MBR systems and their influence in water reuse. Water Sci. Technol. 2013, 67, 894-900. [CrossRef] [PubMed]

17. Cases, V.; Alonso, V.; Argandoña, V.; Rodriguez, M.; Prats, D. Endocrine disrupting compounds: A comparison of removal between conventional activated sludge and membrane bioreactors. Desalination 2011, 272, 240-245. [CrossRef] 
18. Dialynas, E.; Diamadopoulos, E. Integration of a membrane bioreactor coupled with reverse osmosis for advanced treatment of municipal wastewater. Desalination 2009, 238, 302-311. [CrossRef]

19. Jabornig, S. Overview and feasibility of advanced grey water treatment systems for single households. Urban Water J. 2014, 11,361-369. [CrossRef]

20. Liakopoulou, A.; Makropoulos, C.; Nikolopoulos, D.; Monokrousou, K.; Karakatsanis, G. An urban water simulation model for the design, testing and economic viability assessment of distributed water management systems for a circular economy. Environ. Sci. Proc. 2020, 2, 2014. [CrossRef]

21. Dessin-Project. Available online: https:/ / dessin-project.eu/ (accessed on 27 September 2021).

22. Tsoukalas, I.; Kossieris, P.; Makropoulos, C. Simulation of non-gaussian correlated random variables, stochastic processes and random fields: Introducing the anysim r-package for environmental applications and beyond. Water 2020, 12, 1645. [CrossRef] 